\title{
Os Sentidos do Sindicalismo na Veja: o Período da Globalização e Neoliberalismo
}

\section{The Senses of Trade Unionism in Veja: the Period of Globalization and Neoliberalism}

\author{
Guilherme Gustavo Holz Peroni (orcid.org/0000-0003-0670-7501)1 \\ Priscilla de Oliveira Martins-Silva (orcid.org/0000-0002-2922-6607)2 \\ Annor da Silva Junior (orcid.org/0000-0003-4124-5277) 3
}

\begin{abstract}
Resumo
O sindicalismo teve importante participação e influência na política e nos rumos econômicos do Brasil. As mídias influenciam o senso comum, assim como criam e divulgam representações sociais sobre os fenômenos. Com o objetivo de compreender parte do pensamento social da época sobre o sindicalismo, o presente artigo tem como objetivo analisar os sentidos do sindicalismo disseminados pela revista Veja durante o período da globalização e neoliberalismo (1990 a 2002). Para isso, realizou-se uma pesquisa documental na revista Veja, para tal, adotou-se a teoria das representações sociais como aporte teórico, sendo construídas sete categorias de análise. A pesquisa indica uma diversidade de sentidos do sindicalismo, todavia, observa-se uma tendência da Veja em ancorar os sentidos do sindicalismo em valores e significados concernentes aos aspectos da crise do sindicalismo.
\end{abstract}

Palavras-chave: Trabalho. Sindicalismo. Mídias. Representações Sociais.

\begin{abstract}
The trade unionism had an important participation and influence in the politics and the economic directions of Brazil. The media influences common sense, as well as creates and disseminates social representations about the phenomena. In order to understand part of the social thought of the time about trade unionism, the present article aims to analyze the meanings of trade unionism disseminated by Veja during the period of globalization and neoliberalism (1990 to 2002). For this, a documentary research was carried out in Veja magazine; for such, the theory of social representations was adopted as a theoretical background and seven categories of analysis have been constructed. The research indicates a diversity of meanings over trade unionism; however, there is a tendency of Veja to anchor the senses of trade unionism in values and meanings concerning the aspects of the crisis of trade
\end{abstract}

\footnotetext{
${ }^{1}$ Universidade Federal do Espírito Santo, Vitória, Brasil. E-mail: gustavoperoni@ hotmail.com.

${ }^{2}$ Universidade Federal do Espírito Santo, Vitória, Brasil. E-mail: priscillamartinssilva@gmail.com.

${ }^{3}$ Universidade Federal do Espírito Santo, Vitória, Brasil. E-mail: annorsj@gmail.com.
} 
unionism.

Keywords: Labor. Trade unionism. Media. Social Representations. 


\section{Introdução}

Este artigo faz parte de um projeto de pesquisa mais amplo que investigou os sentidos do sindicalismo disseminados por uma parte da mídia escrita (publicações jornalísticas) em quatro períodos históricos: ditadura militar (1968 a 1985); $4^{a}$ república ou redemocratização (1985 a 1990); globalização e neoliberalismo (1990 a 2002); e era Lula e atualidade (2003 a 2013). Verifica-se que as características dos contextos políticos, sociais e econômicos fazem com que o sindicalismo sofra transformações e tenha diferentes sentidos durante os períodos históricos, ou seja, os sentidos do sindicalismo modificaram-se durante a história recente (Alves, 2000; Antunes, 2007, 2015; Boito, 2015; Cardoso, 2002; Ferraz, 2014; Galvão, 2013; Peroni, 2015; Queiroz, 2007; Santana, 2002). Todavia, o presente artigo tem como foco o período denominado como globalização e neoliberalismo (15 de março de 1990 a 31 de dezembro de 2002).

O sindicato é responsável por representar os interesses dos trabalhadores perante o empregador e o governo. $\mathrm{O}$ sindicalismo esteve presente em importantes momentos históricos do Brasil, por exemplo, no golpe contra Vargas, no golpe militar de 1964 e no movimento de redemocratização e das Diretas Já (Boito, 2005). Além disso, o sindicalismo também está relacionado à evolução das relações trabalhistas no Brasil.

Em uma organização, são diversas as reações dos trabalhadores, gerentes e executivos e demais membros perante as ações sindicais. Alguns indivíduos podem ser favoráveis ao sindicato e outros contrários (Lobos, 1988). Dessa forma, diversos sentidos sobre o sindicalismo circulam nas organizações e na sociedade brasileira. As mídias, integradas e atentas ao contexto social, político e econômico, também constroem e divulgam diversos sentidos sobre o sindicalismo. $\mathrm{O}$ estudo sobre as mídias tem sido importante contemporaneamente devido ao profundo desenvolvimento dos meios de comunicação, além da sua perspicaz penetração na vida social e das consequentes transformações produzidas na sociedade (Jovchelovitch, 2000).

Atualmente, a televisão, rádio, jornais, revistas, livros, internet e diversos outros meios de comunicação disseminam diariamente e incessantemente diversas formas simbólicas à sociedade (Brym, Roberts, Lie \& Rytina, 2012; Thompson, 2002), dessa forma, indivíduos que nunca interagiram podem compartilhar as mesmas experiências e memória coletiva devido a sua participação na cultura mediada (Thompson, 2002). Assim, desde o surgimento da comunicação de massa no século XV, com o desenvolvimento das técnicas de impressão por Gutenberg, ocorreram transformações significativas nas formas como os indivíduos recebem, produzem e transmitem diariamente as formas simbólicas (Brym et al., 2012; Thompson, 2002). Thompson (2002) chama esse processo de midiação da cultura moderna, e afirma que tal processo está intimamente relacionado aos desdobramentos do sistema capitalista moderno, fazendo com que as sociedades de diversas partes do mundo tornem-se cada vez mais interligadas.

Nesse contexto, sob uma perspectiva 
crítica, alguns autores julgam a mídia como indutora do pensamento social e individual. Como afirma Guareschi (2003), a mídia beneficia-se do poder simbólico para legitimar as informações difundidas, inculcando-as no pensamento social. Assim, a mídia pode ser responsável por impor conteúdos ao público sem contrapontos, ou seja, a mídia não necessariamente atende à pluralidade de opiniões e à diversidade de pontos de vista sobre determinado assunto (Herz, 2003). Os conteúdos podem ser estruturados e produzidos de forma velada e nem sempre as intenções por detrás da matéria veiculada são aparentes ou explícitas (Herz, 2003).

Os conteúdos difundidos pela mídia, como valores, normas, ideias, concepções e ideologias, tornam-se predominantes no pensamento da população (Herz, 2003). A mídia alimenta e influencia o conhecimento do senso comum, em escala de massas, ela pode tornar-se "particularmente perversa e insidiosa porque se vale de condições, recursos técnicos e linguagens cuja operação e existência sequer é percebida pelo público" (Herz, 2003, pp. 11-12). Nesse sentido, há uma preocupação não somente com o que é comunicado, mas também com a forma que se comunica e com os significados da comunicação para o sujeito e para a sociedade (Alexandre, 2001). De uma única informação pode-se obter diferentes resultados, dependendo de quem dá forma e contornos à mensagem (Schroder, 2003).

Nesse processo, os indivíduos recebem as informações e podem ter um olhar crítico quanto ao conteúdo. Conforme Herz (2003, p. 12), "os conteúdos produzidos e distribuídos pela mídia são assimilados pelo público em um complexo processo de elaboração, que pode envolver mediações críticas em graus variados". Assim, os indivíduos podem adotar uma postura crítica mediante as influências e informações recebidas da mídia (Guareschi, 2003).

Para temáticas que analisam a influência das mídias no pensamento social, a Teoria das Representações Sociais (TRS) oferece o suporte teórico e conceitual. Sobretudo, a TRS surgiu de pesquisas nos meios de comunicação de massa. Em sua obra seminal sobre as Representações Sociais (RS) da Psicanálise, nomeada $L a$ Psychanalyse: Son image et son publique, Moscovici buscou compreender as novas significações da Psicanálise para o senso comum mediante a intermediação dos meios de comunicação (Moscovici, 2012). Diversas pesquisas analisam as mídias por meio da TRS (Espíndula, Alves, Carvalho, Almeida \& Cruz, 2015; Flausino, 1999; Jovchelovitch, 2000; Ordaz \& Vala, 1997; Peroni, 2015). Entretanto, em uma revisão dos artigos científicos brasileiros orientados pela TRS e que adotaram as mídias como lócus de pesquisa, no recorte temporal de 2000 a 2011, Simoneau e Oliveira (2014) constataram que a produção científica que optou pelas mídias como campo de pesquisa ainda é incipiente, se comparada com a produção geral orientada pela TRS. A partir disso, adotou-se a TRS como quadro teórico para a análise dos sentidos do sindicalismo na Veja. A TRS tem como pressuposto analisar o senso comum, para isso propõe-se que as RS são fenômenos complexos e "referem-se às teorias construídas pelo senso comum para explicar a realidade que circunda o indivíduo" (Martins-Silva, Silva Junior, Peroni, 
Medeiros \& Vitória, 2016, p. 894).

Nesse contexto, tem-se como objetivo analisar os sentidos sobre o sindicalismo disseminados pela Veja durante o período da globalização e neoliberalismo (15 de março de 1990 a 31 de dezembro de 2002). Fazem parte dos objetivos específicos: (i) discutir os diferentes posicionamentos da Veja sobre o sindicalismo; (ii) relacionar os discursos da Veja sobre o sindicalismo com as características das relações de trabalho do período; e (iii) discutir o processo de ancoragem das RS do sindicalismo na Veja. Para isso, adotou-se a Veja como lócus de pesquisa devido a sua representatividade e por estar em circulação desde setembro de 1968, abrangendo, portanto, um longo período histórico.

Além disso, a Veja destaca-se no contexto jornalístico brasileiro devido ao seu poder normatizador (Augusti, 2008). Segundo Augusti (2008), a Veja tem autonomia para ditar normas e condutas ao leitor consonantes com os seus valores, crenças, ideologia e cultura. Para isso, a revista utiliza o poder explicativo para tratar de assuntos cotidianos por meio de especialistas e dados comprobatórios, tornandose numa fonte de conhecimento legitimado (Augusti, 2008). Essa fonte de conhecimento legitimado viabiliza a circulação e a formação de RS (Moscovici, 2015) sobre o sindicalismo, objeto de estudo desta pesquisa.

Destacam-se os argumentos que justificam este estudo: (i) a contribuição da TRS para as ciências sociais aplicadas ao apresentar novas formas de compreender e analisar o processo de construção do pensamento social e individual sobre o sindicalismo; (ii) a ausência de estudos documentais que exploram como o sindicalismo é veiculado na mídia brasileira; e (iii) a necessidade de mapear as transformações dos sentidos do sindicalismo na História recente nos veículos de comunicação de massa.

Este artigo consiste de sete seções: na segunda seção, são apresentados os aspectos conceituais da TRS e, em seguida, será discutido o contexto político, social e econômico do período estudado; a quarta seção discorre sobre os aspectos metodológicos da pesquisa; na quinta seção, são apresentados os resultados da pesquisa documental e, na sequência, temos a discussão dos resultados. Por fim, são apresentadas as considerações finais e as limitações da pesquisa.

\section{A Teoria das Representações Sociais: aspectos conceituais}

A TRS foi elaborada por Moscovici em 1961 e tem como principal objetivo compreender o pensamento social (Sá, 2015). O estudo do senso comum tornou-se indispensável para a compreensão das interações sociais e das práticas sociais, pois os indivíduos ou grupos agem e tomam posição a partir da sua visão de mundo (Abric, 2000). A TRS propõe que toda realidade é representada, isto é, a realidade é "reapropriada pelo indivíduo ou pelo grupo, reconstruída no seu sistema cognitivo, integrada no seu sistema de valores, dependente de sua história e do contexto social e ideológico que o cerca" (Abric, 2000, p. 27). Assim, as RS organizam a realidade do indivíduo e orientam as práticas individuais e a dinâmica das relações sociais (Abric, 2000). Com isso, conceituam-se 
as RS como "uma forma de conhecimento, socialmente elaborada e partilhada, com um objetivo prático, e que contribui para a construção de uma realidade comum" (Jodelet, 2001, p. 21).

A principal função das RS é tornar o não familiar em familiar (Moscovici, 2015). Essa função é possível devido aos processos formadores das RS: a objetivação e a ancoragem. A objetivação consiste no processo de tornar um esquema conceitual em algo real, material e concreto (Moscovici, 2015). Já a ancoragem é o processo de classificação de algo estranho e perturbador para o sujeito, inserindo-o numa das categorias existentes (Moscovici, 2015). Por meio da ancoragem, o indivíduo classifica e assimila um novo objeto a um sistema de categorias familiar preexistente, de acordo com o seu sistema de valores e a sua inserção social (Trindade, Souza \& Almeida, 2014). Destarte, um novo objeto "é ancorado quando ele passa a fazer parte de um sistema de categorias já existentes, mediante alguns ajustes" (Trindade, Souza \& Almeida, 2014, p. 146).

A comunicação influencia as RS, pois os indivíduos leem as informações que circulam na mídia e dialogam com outros sujeitos sobre os acontecimentos diários (Duveen, 2015). Nesse sentido, as RS sobre determinado objeto estão em constante (re)construção. As RS “circulam nos discursos, são trazidas pelas palavras e veiculadas em mensagens e imagens midiáticas, cristalizadas em condutas e em organizações materiais e espaciais" (Jodelet, 2001, pp. 17-18). $\mathrm{Na}$ literatura brasileira, é possível encontrar pesquisas científicas que estudam as mídias a partir da abordagem teórica da TRS. Espíndula et al. (2015) investigaram as RS da imprensa sobre o crack e a adolescência. Danfá e Aléssio (2017) analisaram a construção da noção de risco sobre o ebola na revista $V$ eja, enquanto Carvalho e Menandro (2017) discutiram as RS da transposição do rio São Francisco no Jornal Estado de Minas.

Neste artigo, adotou-se a TRS com o objetivo de analisar um entre os diversos elementos das RS do sindicalismo, que são os sentidos do sindicalismo que circulam em uma parte da mídia brasileira. Desse modo, os sentidos do sindicalismo estão adstritos a sensações, por exemplo, percepções e emoções, e a valores, por exemplo, utilidade, importância e classificação apreciativa. Além disso, o contexto político, social e econômico influencia no modo como o sindicalismo é comunicado pela mídia.

\section{O contexto político, social e econômico do período da globalização e neoliberalismo}

O sindicato é um produto do capitalismo e responsável por representar os interesses dos trabalhadores, tendo em vista que o trabalhador individualmente alcançaria resultados insatisfatórios perante o empregador e o governo (Lobos, 1988). Dessa forma, partese do pressuposto que é essencial uma nação ter sindicatos fortes para a melhoria das relações de trabalho e para o alcance de benefícios e acordos que privilegiem a coletividade.

Durante o período Vargas, a legislação trabalhista foi aperfeiçoada e o associacionismo operário foi regulamentado, tornando os sindicatos dependentes da burocracia estatal (Cardoso, 2002). Já o período da ditadura militar 
foi marcado pelo assistencialismo, proibição das greves e perseguição de lideranças sindicais (Cardoso, 2002; Queiroz, 2007). Em 1978, surge o novo sindicalismo em meio ao movimento de renovação do sindicalismo brasileiro, que aconteceu a partir da mobilização dos trabalhadores metalúrgicos do $\mathrm{ABC}$ paulista (Cardoso, 2002). Diante disso, o sindicalismo viveu um período de ascensão devido aos problemas políticos e econômicos vivenciados no Brasil, como a elevada inflação e o desejo de abertura democrática (Santana, 2002).

A história do sindicalismo durante a Era Vargas e a ditadura militar evidenciou a presença do corporativismo estatal e a tutela do Estado, que começaram a ser questionados apenas a partir do surgimento do novo sindicalismo e com o processo de redemocratização (Ferraz, 2014). Como consequência, diversos elementos de liberdade democrática e alterações da estrutura sindical foram incorporados à Constituição Federal de 1988, por exemplo, a restrição da intervenção do governo nos sindicatos, o direito à greve e a liberdade de associação profissional ou sindical (Ferraz, 2014). As políticas neoliberais foram implementadas no Brasil com a eleição de Fernando Collor de Mello (1990 a 1992). Nesse período, foram desenvolvidas as políticas de privatização originárias do Consenso de Washington (Queiroz, 2007). Devido às denúncias de corrupção em seu governo, o presidente Collor foi deposto em 1992 depois de um vasto movimento político e social que reivindicou o seu impeachment (Antunes, 2007). Ademais, grande parte do movimento sindical manifestou-se nas ruas favoravelmente ao impeachment (Santana, 2002). As políticas neoliberais foram retomadas dois anos depois, após a curta presidência de Itamar Franco, com a eleição de Fernando Henrique Cardoso (FHC) em 1994 e, posteriormente, com a sua reeleição em 1998.

O governo de FHC foi responsável pela estabilização da hiperinflação e pela organização das finanças públicas (Costa \& Lamarca, 2013). FHC foi o principal responsável pelo Plano Real, que começou a ser desenvolvido quando ele ainda era Ministro da Fazenda no governo de Itamar Franco (Ianoni, 2009). As políticas neoliberais do período FHC tornaram o Brasil dependente da economia mundial e dos interesses financeiros internacionais, assim como inseriu o país nos novos padrões do processo de reestruturação produtiva do capital (Antunes, 2007). Isso configurou nas modificações dos processos produtivos que transformaram $\mathrm{O}$ mundo do trabalho (Alves, 2000), como a implementação dos processos de downsiz̨ing, que ocasionou a redução do número de trabalhadores, e a adoção das novas formas de gestão produtiva, como o modelo de acumulação flexível (Antunes, 2007). Observouse também a redução da força de trabalho industrial, a ampliação das modalidades de trabalho precarizado, como subempregados, subproletariado e terceirizados (Antunes, 2007), as mudanças tecnológicas e a adesão à Filosofia Toyotista para atender às políticas neoliberais (Alves, 2000). Tais transformações do mundo do trabalho foram fundamentais para a desestruturação da classe trabalhadora e, de certa forma, influenciaram negativamente $o$ sentimento de coletividade e união. 
Destarte, o sindicalismo entra em crise e surge uma nova e precária realidade das relações de trabalho (Alves, 2000). A crise do sindicalismo está intimamente relacionada à perda de legitimidade interna do sindicato, em que ocorre a falta de identificação dos trabalhadores com a organização sindical (Dufour \& Hege, 2010). Assim, nasce um novo tipo de sindicalismo influenciado principalmente pelas modificações processuais do mundo do trabalho, isto é, um sindicalismo com características neocorporativistas e defensivistas; como afirma Alves (2000), um sindicalismo de concertação social. Essas características tendem a enfraquecer a perspectiva de classe, pois são privilegiados os interesses dos membros das cúpulas dos sindicatos e são afastados os anseios da base (Alves, 2000).

Para Faria (2007), a perda de credibilidade dos sindicatos está relacionada ao que ele denomina como fase do colaboracionismo, em que os sindicatos cooperam com as empresas, "agem no lugar da empresa, a favor dela, ainda que justifiquem suas ações como sendo a favor dos empregados" (Faria, 2007, p. 240). Para esses sindicatos, é desvantajoso que as empresas tenham certas dificuldades, como problemas competitivos e a não renovação tecnológica, pois isso pode ocasionar problemas financeiros para as empresas, o desemprego dos trabalhadores e a consequente redução do número de trabalhadores associados ao sindicato (Faria, 2007). A partir dessa lógica de colaboração, esses sindicatos subordinam-se à ordem neoliberal, assim como não têm uma consciência para além do capital (Antunes, 2015).
Com isso, muitos sindicatos brasileiros afastaram-se dos movimentos autônomos, como os movimentos classistas e anticapitalistas, que durante as décadas de 1970 e 1980 lutaram contra as imposições do sistema capitalista (Antunes, 2015). Existem vários exemplos que demonstram essa mudança, um deles é a substituição da luta salarial da década de 1980 pela luta pela garantia de emprego (Santana, 2002). Além disso, verifica-se a presença de uma nova frente de atuação que é de prestação de serviços sociais, em que "o sindicato torna-se uma espécie de organização não governamental e busca se credenciar para executar serviços públicos relegados pelo Estado" (Galvão, 2013, p. 359). Observa-se também que os movimentos sindicais aliaram-se aos novos movimentos populares que surgiram devido ao panorama social e econômico da década de 1990, como o movimento de moradia, a luta dos trabalhadores do setor informal e o movimento dos sem terra (Boito, 2005). Apesar dessas mudanças, algumas correntes minoritárias mantiveram a combatividade (Galvão, 2013)

Inspirado no crescimento do número de sindicatos e da quantidade de trabalhadores sindicalizados nas décadas de 1990 e 2000, Ferraz (2014) afirma que o sindicalismo encontra-se vivo e fortalecido nos dias atuais. Boito (2005) também afirma que é um equívoco afirmar que o sindicalismo entrou em declínio irreversível na década de 1990. Ferraz (2014) demonstra que durante o governo Lula os sindicatos obtiveram algumas conquistas, como o direito de participar de conselhos de políticas públicas e de políticas de valorização do salário mínimo e do emprego. 
Alguns estudos discutem a atuação sindical sob uma perspectiva histórica, assim como os desafios e as transformações do sindicalismo brasileiro na história recente (Alves, 2000; Antunes, 2007, 2015; Boito, 2015; Cardoso, 2002; Ferraz, 2014; Galvão, 2013; Queiroz, 2007; Santana, 2002). Entretanto, torna-se necessária a realização de pesquisas sobre a divulgação do sindicalismo na mídia brasileira sob a perspectiva da Psicologia Social, de forma a compreender como são disseminados os diferentes sentidos sobre o fenômeno social. Assim, propõe-se a realização de uma pesquisa documental que explore as RS do sindicalismo na Veja durante o período da globalização e neoliberalismo.

\section{Método}

\section{Delineamento e fonte de dados}

Os objetivos propostos nesta pesquisa requerem a adoção da pesquisa qualitativa devido às características inerentes a essa abordagem, por exemplo, a descrição detalhada das propriedades dos fenômenos sociais e o exame dos valores, normas e das visões de mundo dos sujeitos estudados (Gelo, Diana \& Benetka, 2008). Adotou-se a consulta a textos jornalísticos como estratégia de coleta de dados, assim, foi realizada uma pesquisa documental na revista semanal Veja (Sá-Silva, Almeida \& Guidani, 2009), sendo que todos os documentos são de conhecimento público e estão disponíveis no acervo digital da revista.

\section{Procedimentos de coleta de dados}

O período histórico investigado iniciase em 15 de março de 1990 e termina em 31 de dezembro de 2002. Selecionou-se uma edição a cada quatro meses e privilegiou-se a primeira edição do respectivo quadrimestre. Para a localização das matérias, foram utilizadas as palavras chaves sindicato(s), sindical(is) e sindicalismo no local de busca do acervo digital da Veja. Todo material foi impresso, inventariado, lido, codificado e analisado e as palavras-chave foram destacadas em todo o material impresso para orientação do pesquisador.

\section{Procedimentos de análise de dados e questões éticas}

A análise de conteúdo foi adotada como método de análise do material classificado (Bardin, 2007). Segundo Flick (2013, p. 134), a análise de conteúdo "é um procedimento clássico para analisar materiais de texto de qualquer origem, de produtos da mídia a dados de entrevistas". Como atividade inicial da análise dos documentos, realizou-se uma leitura flutuante (Bardin, 2007). Em seguida, iniciou-se a leitura das matérias e a elaboração de indicadores. As categorias de análise, a posteriori, foram construídas sob uma dimensão qualitativa e semântica, que tem como objetivo identificar a ausência ou presença de qualidades, significados, sentidos e temas. Assim, buscou-se explorar as unidades de registro pertinentes e, a partir disso, reagrupá-las de acordo com os sentidos comuns desses elementos (Bardin, 2007; Colbari, 2014). A validação externa das categorias foi realizada por três juízes. Depois da categorização dos 
dados, buscou-se produzir inferências sobre as particularidades do texto (Bardin, 2007).

Por fim, destaca-se que não foi necessária a submissão do projeto ao Comitê de Ética em Pesquisa e demais formalidades por se tratar de pesquisa documental com matérias jornalísticas de conhecimento público.

\section{Resultados}

Foi pesquisado no acervo digital da Veja um total de 52 edições, sendo que duas edições foram extras por abordarem assuntos relevantes ao objetivo desta pesquisa. Destaca-se que em sete edições não foram encontradas as palavraschave e cinco edições estavam com problemas de digitalização. Nesses casos, passou-se para a edição subsequente, até que fosse encontrada uma edição com as palavras-chaves. Assim, totalizaram 40 edições válidas e 72 matérias jornalísticas. Todo o material foi analisado e dois artigos foram descartados por abordarem somente o sindicalismo patronal. Por fim, com a análise dos 70 artigos válidos, foram construídas sete categorias de análise. A Tabela 1 apresenta a frequência das categorias de análise, todavia, ressalta-se que as categorias importância dos sindicatos para o país e para os trabalhadores e crise do sindicalismo mostram-se centrais para a compreensão dos sentidos do sindicalismo disseminados pela Veja durante o período da globalização e neoliberalismo.

Tabela 1. Frequência das categorias de análise

\begin{tabular}{lcc}
\hline \multicolumn{1}{c}{ Título da Categoria } & $\begin{array}{c}\text { Frequência } \\
\text { absoluta }\end{array}$ & $\begin{array}{c}\text { Frequência } \\
\text { relativa }\end{array}$ \\
\hline Corrupção, peleguismo e financiamento sindical & 10 & $24 \%$ \\
As transformações do mundo do trabalho & 8 & $20 \%$ \\
Crise do sindicalismo & 7 & $17 \%$ \\
Importância dos sindicatos para o país e para os trabalhadores & 6 & $15 \%$ \\
Novos campos de atuação do sindicalismo & 5 & $12 \%$ \\
Decepção com lideranças sindicais & 3 & $7 \%$ \\
Indivíduos que conquistaram cargo público devido à experiência & 2 & $5 \%$ \\
sindical & & \\
\hline
\end{tabular}

Fonte: Elaborado pelos autores.

A seguir, são apresentadas as categorias de análise e alguns excertos que as exemplificam, os quais estão referenciados da seguinte forma: ano, edição e página.

Importância dos sindicatos para o país e para os trabalhadores (C.1)

Em alguns excertos, os sindicatos foram incluídos no conjunto de entidades importantes para o país. Fizeram parte desses conjuntos, em 
conjunto com os sindicatos: (i) setores político, social, empresarial e universitário; (ii) partidos políticos; (iii) associações de pais e mestres; (iv) clubes; (v) associações de bairro; (vi) entidades de classe; (vii) ordens; (viii) conselhos; (ix) câmara de vereadores; (x) igrejas; e (xi) estudantes. A participação de tais conjuntos no governo foi considerada primordial, por exemplo, para a orientação política do país e no combate à corrupção e à sonegação fiscal.

\section{[...] O PSDB [Partido da Social} Democracia Brasileira] considera que um projeto que envolva sindicatos, empresários e outros partidos poderá dar outro rumo ao país... (Veja, 1991, 1198 , p. 8).

[...] é preciso que as dezenas de milhões de pessoas conscientes e de bem deste país participem cada vez mais ativamente da vida de suas comunidades - desde as associações de pais e mestres até o funcionamento de seus clubes, associações de bairro, entidades de classe, sindicatos e Câmaras de vereadores: somente assim conseguiremos transformar o embalo mágico iniciado em 1992 numa onda gigante que varra do cenário os políticos e empresários comprometidos com os tradicionais esquemas de privilégios e corrupção e abra caminho - já nos próximos anos - para a construção do país que desejamos e ainda merecemos. (Veja, 1993, 1269, p. 78)

\section{Corrupção, peleguismo e financiamento}

\section{sindical (C.2)}

Alguns excertos trataram a forma como os sindicatos eram financiados. Assim, foram discutidos assuntos como: (i) o recebimento de recursos de organizações sindicais do exterior; (ii) as dificuldades financeiras enfrentadas pelos sindicatos; e (iii) o imposto sindical. Alguns trechos indicaram a intempestividade do imposto sindical por financiar sindicatos fantasmas e o peleguismo.

[...] o imposto sindical sempre manteve os sindicatos com dinheiro nos cofres, independentemente de sua força, do número de associados ou do valor de suas contribuições - e com isso criou-se a matriz do peleguismo no Brasil (Veja, 1990, 1146, p. 31)

[...] Ao cortar o imposto através de medida provisória... o presidente Fernando Collor de Mello colocou no mesmo vácuo sindicatos de fachada e entidades que representam de fato os interesses de seus associados... a medida provisória baixada pelo governo pode trazer como consequência, em curto prazo, o desmantelamento de boa parte do movimento sindical... (Veja, 1990, 1146, p. 31)

Alguns excertos também discutiram sobre favoritismos, máfia e corrupção nos sindicatos, por exemplo: (i) empresas obrigadas a remunerar trabalhadores indicados por sindicatos; (ii) monopólio dos sindicatos na contratação de mão de obra nos portos e a 
ineficiência portuária devido à máfia dos portos, representada pelos sindicatos e parlamentares; (iii) prefeituras e sindicatos que arcaram com os custos da candidatura de Lula à Presidência da República; (iv) arrecadação ilegal de fundos pela CUT no exterior para financiar candidaturas do Partido dos Trabalhadores (PT); e (v) sindicatos que financiaram ilegalmente as candidaturas do PT.

A máfia dos portos, sindicatos e parlamentares que os representam... (Veja, 1992, 1233, p. 23)

[...] Resta, no entanto, a pergunta sempre repetida pelos petistas contra os seus adversários: quem paga a conta? "São os militantes do PT que cobrem os custos da Caravana da Cidadania", responde o deputado Chico Vigilante, do PT de Brasília. Mentira piedosa. Quem paga a conta são as prefeituras petistas, como a de Itinga, os sindicatos ligados ao PT, a Central Única dos Trabalhadores e, também, os militantes do partido (Veja, 1993, 1287, p. 26)

[...] Diretor da CUT em São Paulo e presidente do sindicato há dez anos, ele estava brigando com o PT e já havia denunciado que seu próprio sindicato havia feito remessas ilegais de dinheiro para os cofres do partido. "Oswaldo sabia de muitas coisas", diz Luiz Antônio de Medeiros presidente da Força Sindical... Pretendia, segundo Medeiros, mostrar como a CUT arrecada dinheiro no exterior para financiar candidatos do PT, o que é ilegal... (Veja, 1994, 1322, p. 22)

\section{As transformações do mundo do trabalho (C.3)}

Foram encontradas algumas discussões sobre as transformações do mundo do trabalho envolvendo o sindicalismo sobre assuntos como: (i) salário mínimo e antecipações de reajuste salarial; (ii) questões sobre a saúde do trabalhador, como a preocupação com as lesões por esforço repetitivo; (iii) êxodo rural, crescimento da população urbana e mudanças na organização social; (iv) distribuição de renda; (v) crescimento do mercado interno; (vi) revolução industrial e tecnológica e a substituição da mão de obra pela máquina; (vii) recessão e desemprego; (viii) inflação e as perdas salariais; (xi) participação nos lucros das empresas; (x) segurança no trabalho; (xi) férias; e (xii) garantia de emprego antes da aposentadoria. A seguir estão apenas alguns exemplos das discussões apresentadas.

\footnotetext{
[...] Segundo o Sindicato dos Bancários de São Paulo, os caixas fazem em média 400 autenticações de documentos por dia. Há cinco anos, faziam de 150 a 200. O trabalho no caixa simplesmente dobrou. Esse é o terreno propício para a multiplicação das enfermidades catalogadas como lesões por esforço repetitivo. (Veja, 1996, 1460, pp. 52-53)

[...] No ABC, as demissões são a segunda onda desse fenômeno. Cada montadora consegue produzir hoje o dobro de carros que produzia a dez
} 
anos, empregando menos gente... As máquinas $\operatorname{logo}$ se tornam tão baratas que é impossível reduzir salários indefinidamente para concorrer com elas. (Veja, 1999, 1580, p. 102)

Nesse contexto, também foram noticiadas negociações entre sindicatos e empresas sobre assuntos como licença remunerada e redução de salários, da jornada de trabalho e do desemprego. "Quando voltar a funcionar... a indústria automobilística pretende produzir $40 \%$ a menos do que fabricava antes do Plano Collor. Na semana passada, empresas e sindicatos negociavam a redução da jornada de trabalho" (Veja, 1990, 1128, p. 62).

\section{Crise do sindicalismo (C.4)}

O fracasso do sindicalismo também foi discorrido em alguns excertos. Foram relatadas a derrota de determinados sindicalistas, a falta de poder de barganha dos sindicatos e a consequente diminuição do interesse dos trabalhadores pelo sindicalismo. Algumas matérias jornalísticas também demonstraram a crise do sindicalismo ao tratar de assuntos como: (i) o declínio e o abandono do papel revolucionário; (ii) a postura defensivista dos sindicatos; (iii) o risco do corporativismo sindical; (iv) a missão pouco definida dos sindicatos na era pós-industrial; e (v) a grande (e desconhecida) quantidade de sindicatos no Brasil que, supostamente, provocaria a fragmentação do movimento sindical.

[...] o cadáver de Oswaldo Cruz se destina ao cemitério de um movimento sindical que, nascido com tantas promessas de renovação no final da década de 70 , encontrou-se afundado no marasmo, na busca de vantagens pessoais e na defesa de um Estado gordo onde se pendure a comunidade gigantesca que os sindicatos apadrinham. (Veja, 1994, 1322, p. 23)

[...] Os tempos em que tínhamos um poder terrível acabaram, admite Jair Meneguelli, ex-presidente do mesmo sindicato [dos Metalúrgicos do $\mathrm{ABC}$ ]... "O sindicalismo de hoje vive só das glórias do passado", ecoa Luiz Antônio Medeiros, outro antigo militante que foi parar no Congresso Nacional. (Veja, 1999, 1580, p. 101)

Essa falta de poder de barganha dos sindicatos fez diminuir o grau de interesse dos trabalhadores por suas entidades. Os números do IBGE mostram que a proporção de brasileiros filiada a sindicatos caiu quase pela metade... Para se manter de pé, os sindicatos estão buscando alternativas. O dos metalúrgicos de São Paulo chegou a sortear automóveis para atrair filiados... (Veja, 1999, 1580, p. 102)

Alguns excertos também demonstraram que o movimento grevista como instrumento de reivindicação perdeu efeito, devido principalmente aos baixos níveis de emprego, e, por isso, podem ser substituídos por negociações e acordos entre sindicatos e 
empresas.

É hora de acabar com as greves e passar a discutir com os empresários uma forma de manter o emprego, afirma Luiz Marinho, presidente do Sindicato dos Metalúrgicos do ABC. (Veja, 1999, 1580, pp. 100-101)

[...] A mudança de tom durante as negociações é a grande novidade na história do sindicalismo. As greves, que chegaram a 183 por mês a dez anos, agora, quando acontecem, chamam a atenção. Em dezembro, os trabalhadores da Volkswagen aceitaram (sem greve) uma redução salarial de 15\%, como única alternativa a uma demissão em massa. Foi a quebra de um tabu. "Acreditava-se que o emprego era um fato da natureza. Ele simplesmente estava lá, como o Sol estava no céu. A briga era por aumentos salariais", diz o economista José Márcio Camargo... Mas a regra do jogo mudou. A luta agora é pelo emprego. Não pela criação, mas pela manutenção dele. (Veja, 1999, 1580, p. 101)

\section{Novos campos de atuação do sindicalismo (C.5)}

Alguns trechos discorreram sobre as novas formas de atuação do sindicalismo, por exemplo, a aproximação dos sindicatos nas lutas das minorias, como negros, indígenas, homossexuais, mulheres e trabalhadores rurais sem terra.
[...] Nelson Silva, assessor da diretoria do Sindicato dos Bancários de São Paulo (são 135.000 na cidade), tenta há dez anos organizar um grupo de homossexuais (já existem de negros e de mulheres) e não consegue. (Veja, 1993, 1287, p. 53)

[...] Queremos protestar contra 500 anos de latifúndio, disse Valmir Assunção... índios e sem-terra decidiram fazer sua marcha para deixar claro que eram contra o governo. Encontraram reforço junto a integrantes do movimento negro, sindicatos e até um curioso grupo de punks, que aderiu. A polícia ergueu dez barreiras para impedir o acesso dos manifestantes a Porto Seguro e conseguiu barrá-los. (Veja, 2000, 1647, p. 48)

Além disso, os sindicatos e os líderes sindicais também se aproximaram da política, participando, por exemplo, de pesquisas eleitorais, de partidos políticos e propondo uma revisão constitucional para combater a corrupção.

A bandalheira política só vai acabar rapidamente se você participar, ajudando a desamarrar esse nó a partir de agora, na Revisão Constitucional. Com as novas regras políticas propostas pela Força Sindical e pelo Instituto Atlântico, os partidos de aluguel vão acabar e os políticos corruptos vão ter medo de fazer seus negócios milionários. 
(Veja, 1994, 1322, p. 34)

\section{Decepção com lideranças sindicais (C.6)}

A Veja também discutiu sobre a atuação de diversas lideranças sindicais. No entanto, constatou-se em alguns trechos a decepção com o dirigente sindical Antônio Rogério Magri durante o início da década de 1990.

[...] Dirigente sindical de sucesso, Magri era esperado como uma promessa de tempos mais tranquilos na área trabalhista, mas decepcionou os colegas sindicalistas, que criticam o fato de o ministro estar num governo no qual em vez de aumentos de salários se discute redução da jornada de trabalho, salários menores e a hipótese de desemprego em massa... (Veja, 1990, 1128, p. 34)

O presidente da República [Collor], eleito sob o slogan de Caçador de Marajás, já se estrepou duas vezes. Nomeou para o Ministério do Trabalho uma pessoa que ganha salário sem trabalhar... Ninguém deve se esquecer de que o sindicalista Antônio Rogério Magri apresentava-se ao distinto público como antítese dos barbudos petistas na condição de representante do "sindicalismo de resultados". Põe resultado nisso, sindicalista. (Veja, 1991, 1180, p. 19)

\section{Indivíduos que conquistaram cargo público devido à experiência sindical (C.7)}

Também foram encontrados alguns casos de pessoas que ingressaram na política por meio da militância sindical, transmitindo, assim, o sentido de que o sindicalismo seria uma ponte para a obtenção de cargos públicos e para ingressar no meio político.

[...] Homem de origem modesta, filho de imigrante russo, que foi operário, não fez estudos regulares e ingressou na política pela via da militância sindical... (Veja, 1993, 1287, p. 30)

[...] "Ele chegou da Paraíba há dois anos, empregou-se numa empresa de ônibus e entrou no sindicato. Nem sabia o que era partido político", conta João Trigueiro, sindicalista e amigo de Oswaldo... (Veja, 1994, 1322, p. 23)

\section{Discussão}

A presente pesquisa documental explora os sentidos do sindicalismo na Veja durante o período da globalização e neoliberalismo que orientam a formação e a ancoragem de representações sociais. A grande Teoria das Representações Sociais desenvolvida por Moscovici foi adotada como campo teórico. Destaca-se o processo de ancoragem que tem como objetivo ancorar algo estranho e não usual numa categoria familiar e comum (Moscovici, 2015). A seguir, propõe-se discutir o processo de ancoragem dos sentidos do sindicalismo com base em dois aspectos históricos centrais na forma de pensar o sindicalismo: (i) as transformações do mundo do trabalho; e (ii) a atuação sindical, inclusive a atuação política 
devido à associação dos sindicatos aos partidos políticos e centrais sindicais.

Com a eleição de Fernando Collor de Mello no início da década de 1990, o Brasil vivenciou a implementação das políticas neoliberais (Queiroz, 2007). No entanto, o mandato de Collor foi marcado por denúncias de corrupção que derrocaram no processo de impeachment em 1992 (Antunes, 2007). Nesse contexto de instabilidade política e econômica do Brasil, os dados do período da globalização e neoliberalismo demonstram que os sindicatos foram fundamentais para o país, devido à participação destes no combate à sonegação fiscal (C.1) e à corrupção (C.1 e C.5), para o desenvolvimento da democracia e para a luta pelos direitos sociais e trabalhistas e por melhores condições de trabalho e de vida para os trabalhadores (C.1).

A adoção das políticas neoliberais, que foram retomadas por FHC em 1994, ocasionou várias transformações nas relações trabalhistas e nos meios de produção (Queiroz, 2007). Ocorreram diversas transformações no mundo do trabalho, como a intensificação da terceirização, a fragmentação da classe trabalhadora, a desqualificação dos trabalhadores, a substituição da mão de obra por máquinas e o desemprego estrutural (Antunes, 2015). Essas transformações do mundo do trabalho afetaram de forma negativa os sentimentos de união e solidariedade da classe trabalhadora (Faria, 2007).

Nesse ínterim, as transformações do mundo do trabalho (C.3) foram tratadas em alguns excertos como fator para $O$ enfraquecimento do sindicalismo, por exemplo, a reação pacífica dos sindicatos nos casos de demissões em massa e a aceitação da redução salarial devido ao desemprego. Dessa forma, os sindicatos lutaram por aumentos salariais e pelos direitos trabalhistas durante o período da ditadura militar, em contrapartida, mediante as transformações do mundo do trabalho durante o período da globalização e neoliberalismo, os sindicatos começaram a lutar pelo emprego e pela manutenção do trabalho. Nesse contexto, observou-se durante a década de 1990 o surgimento da crise do sindicalismo (Alves, 2000; Antunes, 2015).

Os dados indicam a crise do sindicalismo que foi constituída principalmente pelo desinteresse dos trabalhadores pelo sindicalismo, desprestígio dos sindicatos nas negociações com as empresas e com o governo, postura defensivista dos sindicatos, corporativismo sindical, abandono do papel revolucionário e indefinição da missão dos sindicatos nas nações pós-industrializadas (C.4). O novo sindicalismo não rompeu com o modelo de colaboração com o Estado estabelecido desde o período Vargas (Queiroz, 2007). Segundo Antunes e Silva (2015, p. 525), o novo sindicalismo (re)assumiu nas últimas décadas a "velha prática peleguista, a forte herança estatista e a forte influência do ideário neoliberal (ou social-liberal), impulsionada, ainda, pelo culto da negociação e defesa do cidadão". Com isso, os dados criticam o sindicalismo devido ao não cumprimento de algumas promessas de renovação disseminadas durante o regime militar.

Algumas greves foram relatadas (C.4), porém, os dados caracterizam que os movimentos grevistas perderam efeito devido aos baixos níveis de emprego. Como afirma 
Santana (2002), a luta salarial das décadas de 1970 e 1980 foi substituída pela aspiração de garantia do emprego durante a era neoliberal. A negociação foi indicada como a melhor maneira de trabalhadores e sindicatos discutirem as questões trabalhistas com os empresários (C.3). Dessa forma, os dados tratam da negociação entre sindicatos e empresas ou governo, no entanto, tal negociação nem sempre foi favorável à classe trabalhadora. Devido aos elevados níveis de desemprego, os sindicatos negociaram em alguns casos a redução da jornada de trabalho e a redução de salários com o patronato (C.3).

A Veja também veiculou reportagens sobre o abandono do papel revolucionário e a parceria dos sindicatos com as empresas e o governo (C.4). Faria (2007) salienta a colaboração dos sindicatos com as empresas mediante a lógica neoliberal. De acordo com o autor, os sindicatos tendem a colaborar com as empresas, pois os problemas tecnológicos, competitivos ou financeiros ocasionarão $\mathrm{o}$ desemprego e a consequente redução do número de sindicalizados.

Antunes (2015) afirma que os sindicatos afastaram-se dos movimentos autônomos e anticapitalistas que lutaram contra as imposições do sistema capitalista nas décadas de 1970 e 1980. As manifestações pacíficas, comuns nas nações industrializadas, foram indicadas nos excertos como perda do poder de barganha dos sindicatos, redução do quantitativo de trabalhadores sindicalizados e desinteresse dos trabalhadores pelo sindicalismo (C.4).

O movimento sindical atuou de forma defensiva devido à estagnação da economia e aos altos níveis de desemprego (C.4). De fato, Boito (2005) afirma que, com o advento da era neoliberal e devido a alguns fatores sociais e econômicos, o sindicalismo assumiu uma posição defensiva. $\mathrm{O}$ sindicalismo daquele período se caracterizou pela nova postura de concertação social, em que foi incluída na pauta de resistência dos sindicatos a parceria com as empresas e com o governo (Alves, 2000).

O movimento sindical envolveu-se em outros projetos e inseriu-se em outros espaços (Santana, 2002). Os dados indicam os novos espaços de atuação do sindicalismo, como a aproximação dos sindicatos nas lutas dos negros, indígenas, homossexuais, sem terra e mulheres (C.5). Também se destacou o envolvimento do sindicalismo com a política, como a realização de pesquisas eleitorais e a participação de líderes sindicais e sindicatos no PT e na CUT (C.5). Os dados também indicam certa associação da imagem do sindicalismo como ponte para obtenção de cargos públicos (C.7), pois foram relatados alguns casos de indivíduos que ingressaram na política devido à participação sindical.

A face negativa do sindicalismo também foi retratada pela Veja. Alguns excertos trataram da corrupção nos sindicatos, financiamento ilegal de campanhas eleitorais, arrecadação ilegal de fundos no exterior para o financiamento de campanhas do PT e máfia sindical (C.2). A Veja discutiu sobre a máfia dos portos, em que os sindicatos monopolizaram a contratação da mão de obra. Os exportadores eram obrigados a remunerar os trabalhadores indicados pelos sindicatos. Esse modelo de gestão portuária, com a influência dos sindicatos, foi indicado 
como o principal fator da ineficiência portuária. Ainda de forma negativa, foram discutidos alguns assuntos, como as dificuldades financeiras enfrentadas pelos sindicatos e o imposto sindical. $\mathrm{O}$ imposto sindical foi considerado o principal motivo para o peleguismo e para o financiamento de sindicatos fantasmas e de fachada (C.2).

Diversas lideranças sindicais foram associadas ao sindicalismo. No entanto, principalmente no início da década de 1990, alguns excertos indicaram a associação negativa de Antônio Rogério Magri ao sindicalismo brasileiro (C.6). Magri foi criticado por ter abandonado as lutas sindicais ao assumir $\mathrm{O}$ Ministério do Trabalho no governo de Collor e por ter recebido os salários de seu antigo cargo na Eletropaulo em concomitância aos vencimentos do cargo de Ministro do Trabalho.

Com isso, os dados indicam uma diversidade de nuances dos valores, normas e sentidos do sindicalismo, como a importância dos sindicatos para o país e para os trabalhadores (C.1) e, em contrapartida, a noção de crise do sindicalismo (C.4). Dessa forma, considera-se que a análise das matérias noticiadas na Veja detectou uma pluralidade de sentidos sobre o sindicalismo, ou seja, os sentidos do sindicalismo não são unívocos. Essa pluralidade de sentidos é possível em uma RS. Como afirma Alaya (2014), a dinâmica da realidade social faz com que a interação entre o sujeito e o objeto seja complexa e heterogênea. O campo de estudo TRS manifesta a dinâmica e a complexidade das RS, visto que o sujeito e os grupos sociais têm as suas particularidades culturais, sociais, práticas e de pertença (Jodelet,
2001).

A discussão do processo de ancoragem dos sentidos do sindicalismo a partir das transformações do mundo do trabalho e da atuação sindical apresenta o contexto político, econômico e social em que estão inseridos afetos e valores nos quais estão ancoradas as RS do sindicalismo. Assim, os diversos sentidos veiculados pela Veja estão ancorados nos seguintes valores e significados: relevância, respeito, poder, influência, decepção, desprestígio, crise, fracasso, corporativismo, subordinação, negociação, pacífico, parceiro do capital, defensivismo, peleguismo, corrupção, ilegalidade, político, angariação de recursos e de cargos públicos e financiamento de campanhas.

Diante desses valores e significados, verifica-se que os sentidos veiculados pela $V_{e j a}$ direcionam a formação de uma RS do sindicalismo que o apresenta como fundamental aos trabalhadores e à sociedade e, em contrapartida e preponderantemente, também o delimita como um movimento social em crise (Alves, 2000; Dufour \& Hege, 2010). A crise do sindicalismo torna-se evidente nas matérias jornalísticas publicadas pela Veja ao se analisar principalmente a negociação dos sindicatos com o patronato, a desnecessidade dos movimentos grevistas, o abandono da luta pelos anseios da classe trabalhadora e o envolvimento do sindicalismo com a política em que foram destacados casos de corrupção, o financiamento de campanhas políticas e a aspiração de sindicalistas na obtenção de cargos públicos. Verifica-se, dessa forma, que a Veja impõe um determinado conteúdo e sentido (Guareschi, 2003; Herz, 2003) ao sindicalismo. Em outras 
palavras, observa-se que há uma disseminação de sentidos com valoração negativa relacionados ao sindicalismo.

Nesse ínterim, o sindicalismo viveu durante a globalização e neoliberalismo um período de crise devido às transformações do mundo do trabalho e à atuação política sindical. De certa forma, o enfraquecimento e a subordinação do sindicalismo evidenciam o abandono do papel revolucionário e inovador proposto pelo novo sindicalismo durante o fim da década de 1970.

\section{Considerações finais}

O presente estudo buscou compreender a disseminação de sentidos sobre o sindicalismo na Veja durante o período da globalização e neoliberalismo (1990 a 2002). Para isso, utilizouse a abordagem metodológica qualitativa e foi realizada uma pesquisa documental na revista Veja.

A análise foi guiada pela teoria das representações sociais. A representação social é um "conceito orientado para a descrição dos significados de que são investidos os objetos pertinentes para uma comunidade" (Ordaz \& Vala, 1997, p. 848). Assim, esta pesquisa contribuiu para a análise dos sentidos do sindicalismo partilhados pela Veja, especificamente no campo de construção de saberes e produção de significados (Ordaz \& Vala, 1997). Para isso, tornou-se crucial a compreensão do período histórico da globalização e neoliberalismo, em que se verificaram as transformações do modelo de acumulação capitalista que ocasionaram mudanças em diversos seguimentos da organização trabalhista e, consequentemente, a crise do sindicalismo. A pesquisa identificou que os sentidos do sindicalismo não são unívocos, no entanto, observou-se nas matérias jornalísticas selecionadas para a pesquisa que há uma tendência da Veja em ancorar os sentidos do sindicalismo em valores e significados concernentes aos aspectos da crise do sindicalismo ocasionada pelas transformações do mundo do trabalho e pelas características da atuação sindical durante $\mathrm{o}$ período da globalização e neoliberalismo.

O estudo apresenta algumas limitações, como a não priorização das características morfológicas das matérias jornalísticas, ou seja, a não indicação dos autores que escreveram sobre o sindicalismo, se eram matérias de capa, as ilustrações, os títulos, os tipos de matérias na mesma página e as seções nas quais os artigos foram localizados. Todavia, considera-se que tal limitação não interferiu na análise, pois a quantidade e qualidade dos excertos levantados foram satisfatórias.

A Veja construiu uma imagem de legitimidade e de autenticidade para a divulgação das informações jornalísticas na sociedade. Ademais, acentua-se que a Veja tem normas, valores e ideologias que são aceitos pelo seu público-alvo, composto em sua maioria por indivíduos da classe média (Augusti, 2008; Peroni, 2015). Por outro lado, essas mesmas normas, valores e ideologias são questionadas por um público não leitor da $V_{e j a}$, uma vez que fazem uma leitura crítica do conteúdo disseminado (Guareschi, 2003; Herz, 2003). Esses dois aspectos indicam que a Veja não 
pode ser considerada como fonte de informações neutra.

Com isso, ressalta-se que os fatos noticiados pela Veja de 1990 a 2002 não generalizam ou dimensionam as RS sobre o sindicalismo que circularam na mídia e na sociedade brasileira. Como afirma Flausino (1999, p. 41), "longe de se constituir em espelho do real, a notícia, resultado da linha de produção jornalística, acaba por informar de uma maneira específica". Dessa forma, afirma-se que as matérias selecionadas para este trabalho não são retratos de uma realidade, ou seja, tem-se a consciência de que as RS que circulam sobre o sindicalismo são muito mais heterogêneas e complexas do que se pode examinar no presente estudo. Assim, fica como sugestão a realização de novas pesquisas com essa temática que abranjam outros meios de comunicação de massa.

\section{Referências}

Abric, J. C. (2000). A abordagem estrutural das representações sociais. In A. S. P. Moreira \& D. C. Oliveira (Orgs.). Estudos interdisciplinares de representação social (2a ed., pp. 27-38). Goiânia: AB.

Alaya, D. B. (2014). Abordagens filosóficas e teoria das representações sociais. In Z. A. Trindade, M. F. S. Santos \& A. M. O. Almeida (Orgs.). Teoria das Representações Sociais: 50 anos (pp. 345-374). Brasília: Technopolitik.

Alexandre, M. (2001). O papel da mídia na difusão das Representações Sociais. Comum, 6(17), 111-125. Recuperado em 21 março, 2018, de http://professor.pucgoias.edu.br/SiteDo cente/admin/arquivosUpload/17352/ma terial/opapel $\% 20 \mathrm{da} \% 20 \mathrm{~m} \% \mathrm{C} 3 \%$ ADdia $\% 20$ na $\% 20$ difusao $\% 20 \mathrm{de} \% 20$ representac oes $\% 20$ sociais.pdf.

Alves, G. (2000). Do "novo sindicalismo" à "concertação social": Ascensão (e crise) do sindicalismo no Brasil (1978-1998). Revista Sociologia Política, (15), 111-124. Recuperado em 23 novembro, 2017, de https://repositorio.unesp.br/bitstream/h andle/11449/10829/S010444782000000200008.pdf?sequence=1\&is Allowed $=\mathrm{y}$.

Antunes, R. (2007). Uma breve radiografia das lutas sindicais no Brasil recente e alguns de seus principais desafios. In J. R. Inácio (Org.). Sindicalismo no Brasil: os primeiros 100 anos? (pp. 288-306). Belo Horizonte: Crisálida.

Antunes, R. (2015). Adeus ao trabalho? Ensaio sobre as metamorfoses e a centralidade do mundo do trabalho (16a ed.). São Paulo: Cortez.

Antunes, R., \& Silva, J. B. da. (2015). Para onde foram os sindicatos? Do sindicalismo de confronto ao sindicalismo negocial. Caderno CRH, 28(75), 511-528. Doi: 10.1590/S0103-49792015000300005.

Augusti, A. R. (2008). Os principais valores presentes no discurso jornalístico da revista Veja. Rumores, 1(2), 1-14. Doi: http://dx.doi.org/10.11606/issn.1982677X.rum.2008.51112.

Bardin, L. (2007). Análise de conteúdo (3a ed.). Lisboa: Edições 70.

Boito, A. Jr. (2005). A presença do sindicalismo na História Política do Brasil. In A. Jr. Boito (Org.). O sindicalismo na política brasileira (pp. 265-291). Campinas, SP: Unicamp, Instituto de Filosofia e Ciências Humanas.

Brym, R., Roberts, L., Lie, J., \& Rytina, S. (2012). Sociology: Your compass for a new world. (4a ed.). Toronto: Nelson.

Cardoso, A. M. O. (2002). Sindicalismo no Brasil: breve excurso sobre mudanças e permanências. In A. M. O. Cardoso (Org.). Sindicalismo e relações trabalhistas (pp. 11-34). Rio de Janeiro: Fundação Konrad Adenauer. 
Carvalho, L. A., \& Menandro, M. C. S. (2017). Águas da desunião nacional: representações da transposição do rio São Francisco. Psicologia e Saber Social, 6(1), 1325.

Doi: 10.12957/psi.saber.soc.2017.23717.

Colbari, A. (2014). A análise de conteúdo e a pesquisa empírica qualitativa. In E. M. Souza (Org.). Metodologias e analíticas qualitativas em pesquisa organizacional: uma abordagem teórico-conceitual (pp. 241-272). Vitória: Edufes.

Costa, N. R., \& Lamarca, I. (2013). Os Governos FHC e Lula e a política para a força de trabalho civil do governo central brasileiro. Ciênc. Saúde Coletiva [online], 18(6), 1601-1611. Recuperado em 23 novembro, 2017, de http://www.redalyc.org/html/630/63027 450009/.

Danfá, L., \& Aléssio, R. L. S. (2017). Dimensões alteritárias da ebola no Brasil: um estudo na revista Veja. Psicologia e Saber Social, 6(1), 3-12.

Doi:

10.12957/psi.saber.soc.2017.23554.

Dufour, C., \& Hege, A. (2010). The legitimacy of collective actors and trade union renewal. Transfer: European Review of Labour and Research, 16(3), 351-367. Doi: $10.1177 / 1024258910373865$.

Duveen, G. (2015). Introdução: O poder das ideias. In S. Moscovici (Org.). Representações Sociais: investigaçôes em Psicologia Social (11a ed., pp. 7-28). Petrópolis, RJ: Vozes.

Espíndula, D. H. P., Alves, L. D. S., Carvalho, L. D. A., Almeida, M. B., \& Cruz, S. T. M. (2015). Representações Sociais de crack e adolescência na imprensa pernambucana. Temas em Psicologia, 23(2), 281-292. Doi: 10.9788/TP2015.2-04.

Faria, J. H. (2007). A fase do colaboracionismo: a nova prática sindical. In J. H. Faria (Org.). Análise crítica das teorias e práticas organizacionais (pp. 205-240). São Paulo: Atlas.

Ferraz, A. S. (2014). Novos rumos do sindicalismo no Brasil. Rev. bras. Ci. Soc.,
29(86), 109-123. Recuperado em 23 novembro, 2017, de http://www.scielo.br/pdf/rbcsoc/v29n8 6/08.pdf.

Flausino, M. C. (1999). A voz rouca das manchetes: como Veja mostrou os SemTerra em suas capas. In C. B. Costa, \& M. S. K. Machado (Orgs.). Imaginário $e$ História (pp. 37-48). São Paulo: Marco Zero.

Flick, U. (2013). Introdução à metodologia de pesquisa: um guia para iniciantes. Porto Alegre, RS: Penso.

Galvão, A. (2013). Sindicalismo e neoliberalismo: um exame da trajetória da CUT e da Força Sindical. In R. Antunes (Org.). Riqueza e miséria do trabalho no Brasil II (pp. 353-367). São Paulo: Boitempo.

Gelo, O., Diana, B., \& Benetka, G. (2008). Quantitative and qualitative research: beyond the debate. Integrative Psychological and Behavioral Science, 42(3), 266-290. Doi: 10.1007/s12124-008-9078-3.

Guareschi, P. A. (2003). Construtores da informação: meios de comunicação, ideologia e ética (2a ed.). Petrópolis, RJ: Vozes.

Herz, D. (2003). Prefácio. In P. A. Guareschi. Construtores da informação: meios de comunicação, ideologia e ética (2a ed., pp. 1125). Petrópolis, RJ: Vozes.

Ianoni, M. (2009). Políticas públicas e Estado: o Plano Real. Lua Nova [online], (78), 143183. Recuperado em 23 novembro, 2017, de

http://www.scielo.br/scielo.php?pid=S01 $02-$

64452009000300009\&script=sci_arttext\& tlng=es.

Jodelet, D. (2001). Representações Sociais: um domínio em expansão. In D. Jodelet (Org.). As Representacõos Sociais (pp. 17-44). Rio de Janeiro: Eduerj.

Jovchelovitch, S. (2000). A cobertura da vida pública: Representações Sociais da esfera pública na imprensa. In S. Jovchelovitch (Org.). Representações sociais e esfera pública: a construção simbólica dos espaços públicos no 
Brasil (pp. 89-110). Petrópolis: Vozes.

Lobos, J. A. (1988). Sindicalismo e negociação (3a ed.). Rio de Janeiro: José Olympio.

Martins-Silva, P. O., Silva Junior, A., Peroni, G. G. H., Medeiros, C. P., \& Vitória, N. O. (2016). Teoria das Representações Sociais nos estudos organizacionais no Brasil: análise bibliométrica de 2001 a 2014. Cadernos EBAPE. BR, 14(4), 891-919. Doi : 10.1590/1679-395155900.

Moscovici, S. (2012). A Psicanálise, sua imagem e seu público. Petrópolis: Vozes.

Moscovici, S. (2015). Representacõos Sociais: investigações em Psicologia Social (11a ed.). Petrópolis, RJ: Vozes.

Ordaz, O., \& Vala, J. (1997). Objectivação e ancoragem das Representações Sociais do suicídio na imprensa escrita. Análise Social, 32(143-144), 847-874. Recuperado em 23 novembro, 2017, de http://analisesocial.ics.ul.pt/documentos /1218793753B7iWA0wj8Pl84HM9.pdf.

Peroni, G. G. H. (2015). Os sentidos do sindicalismo na revista Veja: um estudo em Representações Sociais. Dissertação de mestrado em Administração, Universidade Federal do Espírito Santo, Vitória, ES, Brasil.

Queiroz, A. A. (2007). Movimento sindical: passado, presente e futuro. In J. R. Inácio (Org.). Sindicalismo no Brasil: os primeiros 100 anos? (pp. 19-44). Belo Horizonte: Crisálida.

Sá, C. P. (2015). Representações Sociais: o fenômeno, o conceito e a teoria geral. In C. P. Sá (Org.). Estudos de Psicologia Social: História, comportamento, representações e memória. (pp. 183-208). Rio de Janeiro, Eduerj.
Santana, M. A. (2002). O sindicalismo brasileiro nos anos 1980/2000: do ressurgimento à reorientação. In A. M. Cardoso (Org.). Sindicalismo e relaçôes trabalhistas (pp. 35-49). Rio de Janeiro: Fundação Konrad Adenauer.

Sá-Silva, J., Almeida, C. D., \& Guidani, J. F. (2009). Pesquisa documental: pistas teóricas e metodológicas. Rev. Bras. de História \& Ciências Sociais, 1(1), 1-15. Recuperado em 23 novembro, 2017, de https://www.rbhcs.com/rbhcs/article/vi ew/6/pdf.

Schroder, C. Apresentação. (2003). In P. A. Guareschi. Construtores da informação: meios de comunicação, ideologia e ética (2a ed., pp. 11-25). Petrópolis, RJ: Vozes.

Simoneau, A. S., \& Oliveira, D. C. (2015). Representações Sociais e meios de comunicação: produção do conhecimento científico em periódicos brasileiros. Psicologia e Saber Social, 3(2), 281-300. Recuperado em 23 novembro, 2017, de http://www.e-

publicacoes.uerj.br/index.php/psisabersocial/article/view/14478/10957.

Thompson, J. B. (2002). Ideologia e cultura moderna: Teoria Social Crítica na era dos meios de comunicação de massa (6a ed.). Petrópolis, RJ: Vozes.

Trindade, Z. A., Santos, M. F. S., \& Almeida, A. M. O. (2014). Ancoragem: notas sobre consensos e dissensos. In Z. A. Trindade, M. F. S. Santos \& A. M. O. Almeida (Orgs.). Teoria das Representações Sociais: 50 anos (pp. 133-162). Brasília: Technopolitik.

Recebido em: 24/11/2017

Aprovado em: 20/4/2018 